\title{
Serum proteomic, peptidomic and metabolomic profiles in myasthenia gravis patients during treatment with Qiangji Jianli Fang
}

\author{
Chunmei Wang ${ }^{1}$, Yonghai Lu', Zhixi Chen², Xiaobin Liư ${ }^{3}$, Huangquan Lin ${ }^{4}$, Hui Zhao ${ }^{2}$, Jinyan Chen², \\ Yiuwa Kwan ${ }^{4}$ and Saiming Ngai ${ }^{i^{*}}$
}

\begin{abstract}
Background: Qiangji Jianli Fang (QJF) has been used for treatment of myasthenia gravis (MG) in China. However, our understanding of the effects of QJF against MG at the molecular level is limited. This study aims to investigate the effects of QJF treatment of MG patients on the protein, peptide and metabolite levels in serum.

Methods: High-throughput proteomic, peptidomic and metabolomic techniques were applied to investigate serum samples from 21 healthy individuals and 47 MG patients before and after QJF treatment via two-dimensional gel electrophoresis, matrix-assisted laser desorption/ionization time of flight mass spectrometry and liquid chromatography Fourier transform mass spectrometry, respectively.

Results: After QJF treatment, the expression levels of peptides m/z 1865.019, 2021.128 and 1211.668 of complement C $3 f$ increased $(P=0.004, P=0.001$ and $P=0.043$, respectively), while that of peptide $\mathrm{m} / z 1739.931$ of component $\mathrm{C} 4 \mathrm{~b}$ decreased $(P=0.043)$, in the serum of MG patients. The levels of $\gamma$-aminobutyric acid $(P=0.000)$ and coenzyme Q4 $(P=0.000)$ resumed their normal states.
\end{abstract}

Conclusion: QJF could inhibit the activity of the complement system and restore the normal levels of metabolites.

\section{Background}

Myasthenia gravis (MG) is a chronic autoimmune neuromuscular disorder, with an incidence rate of 3-30/ 1,000,000 people per year [1]. MG patients can produce autoantibodies, such as anti-acetylcholine receptor antibody (AChRAb) and anti-muscle-specific receptor tyrosine kinase antibody (MuSKAb) through their own immune system to prevent muscle contraction, and cause muscle weakness and fatigue [2]. Genetic factors play an important role in MG [3]. In addition, infection with viruses or bacteria, such as poliovirus and Escherichia coli, may be involved in the pathogenesis of MG $[4,5]$. Anticholinesterase drugs, non-specific immunosuppressants, thymectomy and plasmapheresis are the main therapeutic approaches to MG [6-8]. However, the above treatments have some serious side effects, such as cardiac arrhythmia, osteoporosis and hypotension, and

\footnotetext{
*Correspondence: smngai@cuhk.edu.hk

'School of Life Sciences, The Chinese University of Hong Kong, Shatin, N.T, Hong Kong SAR, China

Full list of author information is available at the end of the article
}

can not inhibit the relapse of patients' symptoms and achieve complete remission [9]. Alternative treatments with higher efficacy and fewer side effects are required.

Chinese medicine $(\mathrm{CM})$ has been practiced for many diseases, including cancer, cardiovascular disease, inflammation and Parkinson's disease, owing to its long-term efficacy and few side effects [10-14]. The mechanisms of CM immunomodulatory activity have previously been elucidated in several studies, revealing vital roles for immune effector cells, cytokine production and antibody production [15-18].

Qiangji Jianli Fang (QJF) is a CM prescription modified from the Buzhong Yiqi decoction including Radix astragali, Radix codonopsis pilosulae, Atractylodes macrocephala, Radix angelicae sinensis, Cimicifugae rhizoma, Radix bupleuri, Pericarpium citri reticulatae and Radix glycyrrhizae [19]. Previous investigations have demonstrated that QJF exhibits similar efficiency in MG patients to prednisone, and plays long-term protective roles in MG by decreasing the AchRAb level and changing the expression of serum cytokines with fewer side effects

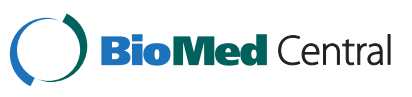


[19-21]. Active components of the herbs in QJF, such as podocarpaside I in Actaea podocarpa and polysaccharide in Angelica acutiloba kitagawa, show characteristic effects on the complement system [22,23]. Herbs such as $R$. bupleuri and $R$. glycyrrhizae are beneficial for autoimmune diseases by inhibiting the production of serum autoantibodies and total IgG (Table 1). However, our understanding of the effects of QJF against MG at the molecular level is limited.

Increased AChRAb and MuSKAb levels were detected in sera from MG patients by enzyme-linked immunosorbent assays [39]. Abnormal serum cytokine levels were also detected [40-42]. In addition, analyses of blood proteomic, peptidomic and metabolomic profiles have been employed to elucidate the pathological mechanisms of diseases and to evaluate the efficiency of drug treatments $[43,44]$. Differentially expressed proteins, peptides and metabolites in serum from MG patients have been compared with those in healthy people by twodimensional gel electrophoresis (2-DE) and mass spectrometry [45-47]. However, no reports have shown the changes in the serum proteomic, peptidomic and metabolomic patterns after QJF treatment.

In this study, high-throughput proteomic, peptidomic and metabolomic techniques were adopted to elucidate the effects of QJF on MG patients using matrix-assisted laser desorption/ionization time-of-flight mass spectrometry (MALDI-TOF MS), 2-DE and liquid chromatography Fourier transform mass spectrometry (LC-FTMS), respectively.

\section{Methods}

Herbs

QJF was produced by the First Affiliated Hospital of Guangzhou University of Chinese Medicine from a boiled water extraction of eight herb components as follows: $60 \mathrm{~g}$ of $R$. astragali, $30 \mathrm{~g}$ of $R$. codonopsis pilosulae, $15 \mathrm{~g}$ of $A$. macrocephala, $10 \mathrm{~g}$ of $R$. angelicae sinensis, $10 \mathrm{~g}$ of C. rhizoma, $10 \mathrm{~g}$ of $R$. bupleuri, $5 \mathrm{~g}$ of $P$. citri reticulatae and $5 \mathrm{~g}$ of $R$. glycyrrhizae. Compared with the herb levels in the Buzhong Yiqi decoction, QJF contained decreased levels of P. citri reticulatae (5 g vs. $6 \mathrm{~g}$ ) and $R$. glycyrrhizae (5 g vs. $9 \mathrm{~g} R$. glycyrrhizae preparata) and increased levels of $R$. astragali (60 g vs. $18 \mathrm{~g}$ ), $R$. codonopsis pilosulae (30 g vs. 6 g Panax ginseng), A. macrocephala (15 g vs. $9 \mathrm{~g}), R$. angelicae sinensis (10 g vs. $3 \mathrm{~g}$ ), C. rhizoma (10 g vs. $6 \mathrm{~g}$ ) and $R$. bupleuri (10 g vs. 6 g). The herbs were purchased from Zhixin Medicine Health Co. Ltd. (China) and identified by the School of Chinese Pharmaceutical Science, Guangzhou University of Chinese Medicine, China. For the extraction, the herbs were boiled in four volumes of water for $1 \mathrm{~h}$, and the extraction step was repeated once. The two extracts were mixed together for use.

\section{Participants}

This study was approved by Ethics Commitee of Guangzhou University of Chinese Medicine, and all participants provided informed consent according to institutional guidelines. Peripheral blood samples were obtained from 47 patients (18 males and 29 females; average age: 40 years) diagnosed with MG in the First Affiliated Hospital of Guangzhou University of Chinese Medicine. All MG patients were confirmed by the neostigmine test. According to the Osserman classification [48], 4 patients were class I, 34 patients were class II (17 class IIa; 17 class IIb), 4 patients were class IV and 5 patients were class V. All the patients were treated with QJF orally once per day for 2 months. Peripheral blood samples from 21 healthy individuals (10 males and 11 females; average age: 34 years) were collected as controls.

\section{Preparation of serum samples}

Before and after the 2-month treatment, blood samples were collected, allowed to clot at $4{ }^{\circ} \mathrm{C}$ overnight and centrifuged at $1,000 \times g$ for $10 \mathrm{~min}$. The sera were collected and frozen in aliquots for storage at $-80{ }^{\circ} \mathrm{C}$ until analysis.

\section{Albumin/lgG depletion}

A Qproteome Albumin/IgG Depletion Kit (Qiagen, USA) was used for depletion of albumin and IgG from the serum samples according to the manufacturer's

Table 1 Herbal components of QJF and their reported active ingredients with immunomodulatory effects

\begin{tabular}{lll}
\hline \multicolumn{1}{c}{ Herbs } & \multicolumn{1}{c}{ Active ingredients } & References \\
\hline R. astragali & Polysaccharides; flavonoids; saponins & {$[24-26]$} \\
R. codonopsis pilosulae & Polysaccharide & {$[27,28]$} \\
A. macrocephala & Glycoprotein & {$[29,30]$} \\
R. angelicae sinensis & Sulfated polysaccharide & {$[31]$} \\
C. rhizoma & Cycloartane glycosides; cyclolanostane triterpene diglycosides & {$[32,33]$} \\
R. bupleuri & Bupleurum polysaccharides; saikosaponin & {$[34,35]$} \\
Pericarpium citri reticulatae & Synephrine & {$[36]$} \\
R. glycyrrhizae & Glycyrrhiza polysaccharide; liquiritigenin & {$[37,38]$} \\
\hline
\end{tabular}


instructions. Briefly, an aliquot of serum $(50 \mu \mathrm{L})$ was applied to a depletion spin column and the eluate was collected by centrifugation at $500 \times g$ for $10 \mathrm{~s}$. The samples were desalted by acetone (Merck, Germany) precipitation and resuspended in buffer comprising $7 \mathrm{M}$ urea (GE Healthcare, Sweden), 2 M thiourea (GE Healthcare, UK), 2\% (w/v) 3-[(3-cholamidopropyl)-dimethylammonio]-1-propanesulfonate (CHAPS) (USB, Germany) and $1 \%(w / v)$ dithiothreitol (USB, Canada). Subsequently, the samples were quantified using a PlusOne ${ }^{\mathrm{Tm}} 2 \mathrm{D}$ Quant Kit (GE Healthcare, Sweden) according to the manufacturer's instructions.

\section{Two-dimensional gel elctrophoresis}

2-DE experiments were performed following the protocol of GE Healthcare Life Science with some modifications. Albumin/IgG-depleted sera $(100 \mu \mathrm{g})$ were loaded onto immobilized $\mathrm{pH}$ strips $(\mathrm{pH} 3-10)$ of $13 \mathrm{~cm}$ in length. Isoelectric focusing was performed using an $\mathrm{Ettan}^{\text {Tux }}$ IPGphor $^{\text {Tx }}$ Isoelectric Focusing System (GE Healthcare, Sweden) with a total voltage hours (Vhs) of 38890 Vhs. The IPG strips were sequentially equilibrated in buffer $(50 \mathrm{mM}$ Tris-HCl, $\mathrm{pH} 8.8,6 \mathrm{M}$ urea, 30\% (v/v) glycerol, $2 \%(w / v)$ SDS, $0.002 \%(w / v)$ bromophenol blue) containing dithiothreitol $(10 \mathrm{mg} / \mathrm{mL})$ and iodoacetamide (25 mg/mL; GE Healthcare, UK) for 15 min before separation by $11 \%$ sodium dodecyl sulfate polyacrylamide gel electrophoresis. The gels were silver-stained and analyzed using ImageMaster ${ }^{\mathrm{Tm}}$ 2D Platinum ver. 5.0 software (GE Healthcare, Sweden). The experiment was repeated three times. Differentially expressed protein spots $(\geq 1.5$-fold) were excised. After in-gel digestion with $20 \mathrm{ng} / \mu \mathrm{L}$ trypsin (Promega, USA), the peptides were extracted with $2.5 \%$ trifluoroacetic acid (Sigma, Germany) and 80\% acetonitrile (ACN) (Merck, Germany) for mass spectrometry.

\section{Peptide capture}

Peptides in serum were extracted using Dynabeads RPC 18 (Invitrogen Dynal AS, Norway) according to the manufacturer's instructions. Serum $(50 \mu \mathrm{L})$ was added to a vial containing $20 \mu \mathrm{L}(0.25 \mathrm{mg})$ of Dynabeads and incubated at room temperature for $5 \mathrm{~min}$. Peptides were eluted with $10 \mu \mathrm{L}$ of $80 \% \mathrm{ACN}$ for mass spectrometry.

\section{Mass spectrometry}

Peptide solution $(1.5 \mu \mathrm{L})$ extracted from a $2 \mathrm{D}$ gel spot or captured from serum was spotted onto a MALDI target plate, followed by spotting of $0.5 \mu \mathrm{L}$ of $\alpha$-cyano- 4 -hydroxy-cinnamic acid (Sigma, USA). Peptides with the mass range $m / z$ 700-4000 were detected using a 4700 MALDI-TOF/TOF mass spectrometer (Applied Biosystems, USA) in the reflectron positive-ion mode and accumulated from 2000 laser shots with acceleration of $20 \mathrm{kV}$. The MS spectra were internally calibrated using porcine trypsin autolytic products $(\mathrm{m} / z$ 842.509, 1045.564, 1940.935 and 2211.104). The MS peaks $\left(\mathrm{MH}^{+}\right)$ were detected with a minimum $\mathrm{S} / \mathrm{N}$ ratio of $\geq 20$ and a cluster area $\mathrm{S} / \mathrm{N}$ threshold of $\geq 25$ without smoothing or raw spectrum filtering. Peptide precursor ions corresponding to contaminants, including keratin and the trypsin autolytic products, were excluded with a mass tolerance of $\pm 0.2 \mathrm{Da}$. The filtered precursor ions with a defined threshold $(\mathrm{S} / \mathrm{N}$ ratio $\geq 50)$ were selected for the MS/MS scan. Fragmentation of precursor ions was performed using the MS/MS $1-\mathrm{kV}$ positive mode with collision-induced dissociation on and argon as the collision gas. MS/MS spectra were accumulated from 3000 laser shots using default calibration with GluFibrinopeptide B (Applied Biosystems, USA). The MS/ MS peaks were detected for a minimum $\mathrm{S} / \mathrm{N}$ ratio of $\geq 3$ and a cluster area $\mathrm{S} / \mathrm{N}$ threshold of $\geq 15$ with smoothing.

\section{Metabolomic analysis}

Serum was transferred into an Eppendorf tube and diluted three-fold (v/v) with ACN. The mixture was shaken vigorously for $30 \mathrm{~s}$. After centrifugation at $9,600 \times g$ for $10 \mathrm{~min}$ at room temperature, the supernatant was analyzed using a Dionex Ultimate 3000 2D Nanoflow LC System (Bruker Daltonics Inc., USA) coupled to an Apex Ultra 7.0 Hybrid Qh-FTMS (Bruker Daltonics Inc., USA) equipped with an electrospray ionization source. An Atlantis T3 $3 \mu \mathrm{m}$ column $(2.1 \mathrm{~mm}$ i.d. $\times 150 \mathrm{~mm}$; Waters, USA) was used. The column was maintained at $35{ }^{\circ} \mathrm{C}$. The mobile phases $\mathrm{A}$ and $\mathrm{B}$ were water with $0.1 \%$ formic acid (Sigma, USA) and ACN with $0.1 \%$ formic acid, respectively. The gradient duration program was: $0-2 \mathrm{~min}, 5 \% \mathrm{~B} ; 2-17 \mathrm{~min}, 5-95 \% \mathrm{~B}$; $17-20 \mathrm{~min}, 95 \% \mathrm{~B}$; and $20-21 \mathrm{~min}, 95-5 \% \mathrm{~B}$. The flow rate was $0.2 \mathrm{~mL} / \mathrm{min}$. The spectra were acquired over the $m / z 50-1000$ range in the positive ion mode. The capillary voltage and spray shield were set to 4200 and $3500 \mathrm{~V}$, respectively. The dry gas was set to $6 \mathrm{~L} / \mathrm{min}$ at a temperature of $200{ }^{\circ} \mathrm{C}$. The neb gas was set to $3 \mathrm{~L} / \mathrm{min}$.

\section{Data processing}

The MS and MS/MS data acquired by MALDI-TOF MS were loaded into GPS Explorer ${ }^{\text {Tx }}$ software ver. 3.5 (Applied Biosystems, USA) and searched against the NCBInr human database using the Mascot search engine (Matrix Science, UK) for protein and peptide identification. The following search parameters were used: monoisotopic peptide mass $\left(\mathrm{MH}^{+}\right)$; mass range, 700-4000 Da; one missed cleavage per peptide; enzyme, trypsin (no enzyme was selected for serum peptide data searching); taxonomy, human; pI, 0-14; precursor ion mass tolerance, $50 \mathrm{ppm}$; MS/MS fragment ion mass tolerance, $0.1 \mathrm{Da}$; and variable modifications, oxidation for 
methionine (no modification was selected for serum peptide data searching). Known contaminant ions corresponding to keratin and/or trypsin were excluded from the peak lists before database searching. Protein score was calculated automatically by Mascot search engine based on the comparison of peptide masses and peptide fragment ion masses to amino acid sequences in database. The top ten hits for each protein search were reported. Proteins with MOWSE scores above 70 and at least four matched peptides were accepted as identified. The spectra of the captured serum peptides were imported to Markerview ${ }^{\text {mix }}$ software ver. 1.2.0.6 (Applied Biosystems/MDS SCIEX, USA) using the following spectra processing options: mass tolerance, $50 \mathrm{ppm}$; minimum required response, 200; and maximum number of peaks, 20000.

LC-FTMS data were exported by Data Analysis ver. 4.0 software (Bruker Daltonics Inc., USA) and analyzed by SIMCA-P ver. 12.0 software (Umetrics AB, Sweden). The data were presented as the mean \pm standard deviation (SD). The significance of differences was evaluated by Student's $t$-test using SPSS 13.0 for Windows software (SPSS Inc., USA). $P$ values less than 0.05 were considered statistically significant.

\section{Results and discussion}

In this study, three approaches were applied to investigate the changes in the serum profiles of MG patients during QJF treatment. The proteomic approach detects serum proteins of $>20 \mathrm{kDa}$, the peptidomic approach evaluates peptides with a mass range of 700-4000 Da and the metabolomic approach investigates metabolites of $<1000 \mathrm{Da}$. Although serum proteins, peptides and metabolites can serve as biomarkers to indicate the progression of a diseased state, changes in the processed products, such as peptides and metabolites, can be more complementary to a certain diseased state and drug treatment.

\section{Serum proteomic profiles}

Arbitrarily combined serum samples from healthy controls and MG patients before and after QJF treatment were prepared, respectively. Before the proteomic analysis, most of the highly abundant proteins, such as albumin and IgG, were depleted from the serum samples. 2-DE and MALDI-TOF MS were performed to identify differentially expressed proteins in the serum samples from the different groups.

In the 2-DE gels, ten differentially expressed spots were detected in the serum of MG patients compared with the healthy controls (Figure 1). Five proteins were identified in these ten spots through MALDI-TOF MS and NCBI database searches. Among them, $\alpha$-2-macroglobulin, gelsolin and hemopexin were downregulated (decreases of
2.49-, 1.91- and 2.07-fold with $P=0.002,0.046$ and 0.011 , respectively) while haptoglobin and haptoglobin-related protein were upregulated (increases of 1.58- and 2.62-fold with $P=0.062$ and 0.005 , respectively) in the serum of MG patients compared with healthy controls (Table 2), suggesting immunoreactivity in the MG patients. In the serum of ankylosing spondylitis patients, another autoimmune disease, haptoglobin and its precursor were reported to show significant increases $[49,50]$. The similar results observed in MG patients in the present study further confirm their roles in the pathological process of autoimmune diseases. $\alpha$-2-macroglobulin is a carrier protein for hormones and an inhibitor of proteolytic enzyme activities [51], and its decrease induces abnormalities in protease metabolism in MG patients. The decrease in hemopexin in the serum of MG patients may reflect an anemic state during the chronic process [52].

To evaluate the effects of QJF on MG patients, the serum proteomic profiles of MG patients before and after treatment were compared using the above method. However, no differentially expressed proteins were identified, even in the five proteins listed above, indicating that QJF cannot reverse the expression changes in these proteins.

\section{Serum peptidomic profiles}

The serum peptides of all samples were extracted using Dynabeads and analyzed by MALDI-TOF MS. Around 278 peptides within the mass range of $\mathrm{m} / z$ 700-4000 were extracted from the raw spectra using the spectra processing options described in the Methods section. Through MarkerView ${ }^{\text {Tw }}$ ver. 1.2 software analysis, 16 peptides identified as six proteins showed significant decreases $(P<0.05)$ in MG patients and seven peptides changed their quantities after QJF treatment $(P<0.05)$ (Table 3).

The expression levels of complement C3f peptides, such as $m / z$ 1777.922, 1865.019, 1934.125 and 2021.128, were significantly decreased in MG patients, while the expression of complement C3f peptides $\mathrm{m} / \mathrm{z}$ 1865.019, 2021.128 and 1211.668 were increased after QJF treatment (Table 3). Complement C3f is the released inactive peptide from component C3 [53], suggesting that QJF could increase the degradation of $\mathrm{C} 3$ and alleviate the high level of this complement component in the blood of MG patients.

The complement C3 level is correlated with the clinical severity of AChRAb-positive generalized MG [54]. Suppressed anti-AChR IgG production and deposition of attack complexes at the endplates were found in $\mathrm{C} 3$ (-/-) mice, which showed resistance to MG [55]. Therefore, QJF could be beneficial to MG patients via degradation of complement component C3.

Peptide $\mathrm{m} / \mathrm{z} 1739.931$ of complement C4b decreased after QJF treatment (Table 3). C4b is a part of C3- 


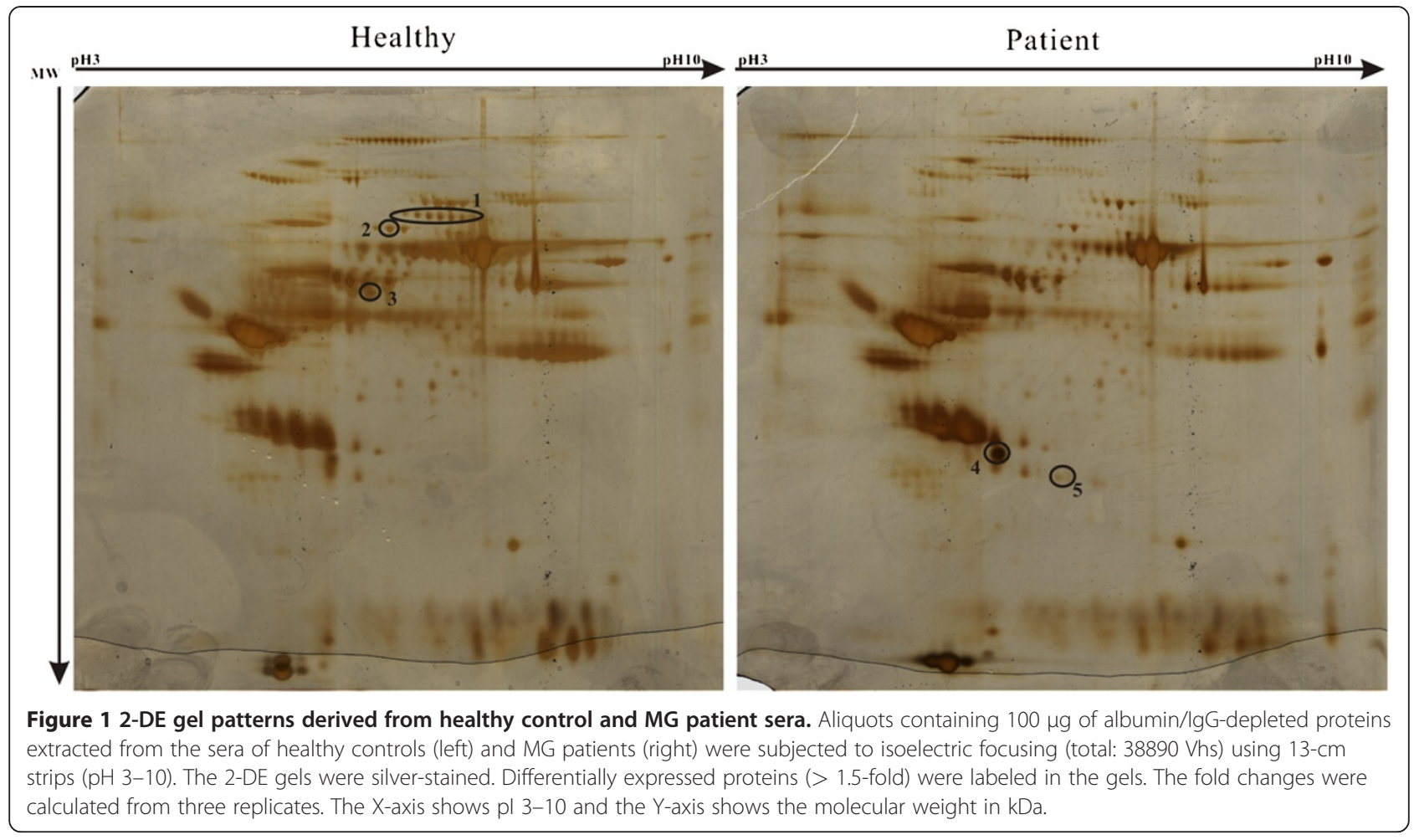

convertase and takes part in C3 activation, which influences the production of active C3b [56]. The mechanism of the QJF effect on the immunoreactivity could involve an increase in the degradation of complement $\mathrm{C} 3$ and a decrease in the production of the active complement $\mathrm{C} 3$ fragment. These findings suggest that inhibition of complement components is a potential therapeutic strategy with high efficacy for autoimmune diseases, including MG [7,57].

Kallidin II was decreased in MG patients (decrease of 1.442-fold compared with healthy controls), and remained decreased even after QJF treatment (decrease of 3.698-fold compared with untreated MG patients) $(P=0.000)$ (Table 3$)$. Kallidin is a pro-inflammatory kinin peptide that acts as a stimulant for several inflammatory cytokines, such as tumor necrosis factor, interleukin-1 and interleukin-6, and is involved in many physiological and pathological processes [58]. Abnormal serum cytokine levels were shown to be related to the pathogenesis of MG [40]. The decrease in kallidin II after QJF treatment may inhibit the stimulation of cytokines and reduce the activity of inflammatory molecules in MG patients.

Peptides belonging to $\alpha$-fibrinogen precursor, fibrinoligase and prothrombin were also detected in this study. These proteins are involved in blood coagulation. Upon QJF treatment, most of the peptides showed no change, except for the increase in peptide $\mathrm{m} / \mathrm{z} 1020.516$ $(P=0.000)$ and the decrease in peptide $\mathrm{m} / z 2553.160$ $(P=0.005)$. However, no studies have shown their associations with MG.

\section{Serum metabolomic profiles}

In our previous study [47], nine differentially expressed metabolites were identified in the serum of MG patients, including $\gamma$-aminobutyric acid (GABA), coenzyme $\mathrm{Q}$,

Table 2 Differentially expressed proteins in the serum profiles of MG patients

\begin{tabular}{|c|c|c|c|c|c|c|}
\hline Spot & Protein name & $\begin{array}{l}\text { Accession Number } \\
\text { (Swiss-Prot) }\end{array}$ & $\begin{array}{l}\text { No. of matched } \\
\text { peptides }\end{array}$ & $\begin{array}{l}\text { Protein } \\
\text { score }\end{array}$ & $\begin{array}{c}\text { Fold } \\
\text { change }^{a}\end{array}$ & $P$ value $^{b}$ \\
\hline 1 & a-2-macroglobulin & P01023 & 17 & 207 & -2.49 & 0.002 \\
\hline 2 & Gelsolin & P06396 & 10 & 90 & -1.91 & 0.046 \\
\hline 3 & Hemopexin & P02790 & 13 & 180 & -2.07 & 0.011 \\
\hline 4 & Haptoglobin & P00738 & 12 & 134 & 1.58 & 0.062 \\
\hline 5 & Haptoglobin-related protein & P00739 & 10 & 148 & 2.62 & 0.005 \\
\hline
\end{tabular}

${ }^{a}$ The ratio of the volume percentage (vol \%) between MG patient and healthy control.

${ }^{\mathrm{b}} P$ values were calculated by Student's $t$-test. 
Table 3 Differentially expressed peptides in the serum profiles of MG patients before and after QJF treatment

\begin{tabular}{|c|c|c|c|c|c|c|c|c|}
\hline \multirow[t]{2}{*}{ Protein name } & \multirow[t]{2}{*}{ Peptide mass } & \multirow[t]{2}{*}{ Sequence } & \multicolumn{3}{|c|}{ Patient $(\mathrm{P})$ vs. healthy control(C) } & \multicolumn{3}{|c|}{ After (A) vs. Before (B) treatment } \\
\hline & & & Change & $P$ value & $\begin{array}{c}\text { Fold change } \\
(C / P)\end{array}$ & Change & $P$ value & $\begin{array}{l}\text { Fold change } \\
\text { (B/A) }\end{array}$ \\
\hline \multirow[t]{5}{*}{ Complement C3f } & 1777.922 & SKITHRIHWESASLL & Down & 0.000 & 1.808 & - & - & - \\
\hline & 1865.019 & SSKITHRIHWESASLL & Down & 0.000 & 2.311 & Up & 0.004 & 0.582 \\
\hline & 1934.125 & SKITHRIHWESASLLR & Down & 0.043 & 1.412 & - & - & - \\
\hline & 2021.128 & SSKITHRIHWESASLLR & Down & 0.000 & 2.488 & Up & 0.001 & 0.364 \\
\hline & 1211.668 & RIHWESASLL & - & - & - & Up & 0.043 & 0.753 \\
\hline \multirow[t]{2}{*}{ Component C4b } & 1625.975 & NGFKSHALQLNNRQ & Down & 0.010 & 5.421 & - & - & - \\
\hline & 1739.931 & NGFKSHALQLNNRQI & Down & 0.013 & 2.295 & Down & 0.043 & 1.567 \\
\hline Kallidin II & 904.682 & RPPGFSPF & Down & 0.003 & 1.442 & Down & 0.000 & 3.698 \\
\hline \multirow[t]{8}{*}{ a-fibrinogen precursor } & 905.452 & FLAEGGGVR & Down & 0.020 & 2.625 & - & - & - \\
\hline & 1020.516 & DFLAEGGGVR & Down & 0.001 & 3.435 & Up & 0.000 & 0.381 \\
\hline & 1077.550 & GDFLAEGGGVR & Down & 0.001 & 2.156 & - & - & - \\
\hline & 1206.605 & EGDFLAEGGGVR & Down & 0.023 & 4.059 & - & - & - \\
\hline & 1350.655 & SGEGDFLAEGGGVR & Down & 0.019 & 2.284 & - & - & - \\
\hline & 1465.701 & DSGEGDFLAEGGGVR & Down & 0.041 & 3.008 & - & - & - \\
\hline & 2931.280 & SSSYSKQFTSSTSYNRGDSTFESKSY & Down & 0.006 & 2.025 & - & - & - \\
\hline & 2553.160 & SSSYSKQFTSSTSYNRGDSTFES & - & - & - & Down & 0.005 & 1.409 \\
\hline Fibrinoligase & 2602.337 & AVPPNNSNAAEDDLPTVELQGWPR & Down & 0.043 & 1.824 & - & - & - \\
\hline Prothrombin & 1389.686 & TSEYQTFFNPR & Down & 0.044 & 1.675 & - & - & - \\
\hline
\end{tabular}

Note: "-"indicates that the peptide showed no differential expression.

pipecolic acid, 5,8-tetradecadienoic acid, sphingosine-1phosphate, bisnorcholic acid, chenodeoxycholylglycine, coprocholic acid and cholylglycine. In the present study, we compared the serum metabolic profiles in MG patients before and after QJF treatment by LC-FTMS. Eight metabolites with significant changes in abundance after QJF treatment were identified (Table 4). The results showed that the GABA level was increased after QJF treatment. GABA has an inhibitory role in autoimmune inflammation, and an inefficient GABA signaling system may result in unchecked proinflammatory cytokine production via the p38 MAPK pathway [59,60]. Therefore, QJF could improve the deficiency status of GABA in the serum of MG patients.

Coenzyme Q4 was a detected metabolite with decreased expression after QJF treatment. Coenzyme Q4 is a member of the ubiquinone family. Ubiquinone and ubiquinol have protective effects on serum low-density lipoprotein from lipid peroxidation [61]. Another ubiquinone coenzyme, Q10, exerts anti-inflammatory properties

Table 4 Serum metabolite profiles of MG patients before and after QJF treatment

\begin{tabular}{|c|c|c|c|c|c|c|}
\hline \multirow[t]{2}{*}{ Metabolite } & \multirow[t]{2}{*}{ Formula } & \multirow[t]{2}{*}{ $\pm p^{p} m^{a}$} & \multicolumn{2}{|c|}{ Peak area $\left(\right.$ Mean $\left.\pm S D^{b}\right)$} & \multirow[t]{2}{*}{$\%$ Change $^{c}$} & \multirow[t]{2}{*}{$P$ value } \\
\hline & & & Before therapy & After therapy & & \\
\hline Y-aminobutyric acid & $\mathrm{C}_{4} \mathrm{H}_{9} \mathrm{NO}_{2}$ & -71.7 & $10.2 \pm 0.52$ & $15.80 \pm 0.81$ & 54.9 & 0.000 \\
\hline Coenzyme Q4 & $\mathrm{C}_{29} \mathrm{H}_{42} \mathrm{O}_{4}$ & 43.1 & $12.28 \pm 3.41$ & $7.89 \pm 0.89$ & -35.7 & 0.000 \\
\hline Taurallocholic acid & $\mathrm{C}_{26} \mathrm{H}_{45} \mathrm{NO}_{7} \mathrm{~S}$ & -75.8 & $0.03 \pm 0.17$ & $6.72 \pm 5.32$ & 19016.7 & 0.000 \\
\hline Dipalmitoylphosphatidic acid & $\mathrm{C}_{35} \mathrm{H}_{69} \mathrm{O}_{8} \mathrm{P}$ & 92.9 & $0.19 \pm 0.38$ & $6.65 \pm 2.35$ & 3397.8 & 0.000 \\
\hline Phytosphingosine & $\mathrm{C}_{18} \mathrm{H}_{39} \mathrm{NO}_{3}$ & -2.3 & $1.73 \pm 1.53$ & $19.11 \pm 7.29$ & 1004.8 & 0.000 \\
\hline 5b-Cyprinolsulfate & $\mathrm{C}_{27} \mathrm{H}_{48} \mathrm{O}_{8} \mathrm{~S}$ & -50.2 & $0.38 \pm 0.61$ & $2.63 \pm 2.01$ & 591.9 & 0.000 \\
\hline Thromboxane B2 & $\mathrm{C}_{20} \mathrm{H}_{34} \mathrm{O}_{6}$ & 40 & $1.13 \pm 1.45$ & $2.92 \pm 1.91$ & 158.3 & 0.000 \\
\hline Biliverdin IX & $\mathrm{C}_{33} \mathrm{H}_{34} \mathrm{~N}_{4} \mathrm{O}_{6}$ & 3.6 & $22.71 \pm 5.78$ & $6.36 \pm 3.54$ & -71.9 & 0.000 \\
\hline
\end{tabular}

${ }^{a}$ Mass differences between the calculated and measured metabolite masses.

${ }^{\mathrm{b}}$ Mean peak areas of metabolites in patients before and after QJF treatment. SD denotes standard deviation.

${ }^{c}$ Changes are calculated as the difference in the median concentrations before and after QJF treatment.

${ }^{\mathrm{d}} P$ values were calculated by Student's $t$-test. 
via NF-kB1-dependent gene expression [62]. However, no reports have suggested a function for coenzyme Q4 in serum, and the issue of whether it exerts antiinflammatory properties requires further investigation.

In addition to the above two metabolites, six other metabolites also changed their quantities following QJF treatment, although no changes were detected in MG patients compared with normal healthy controls. Among these metabolites, phytosphingosine and dipalmitoylphosphatidic acid have anti-inflammatory effects $[63,64]$. The increased level of thromboxane $\mathrm{B} 2$, an inactive product of thromboxane A2, may improve the high coagulation state of MG patients, while the decrease in biliverdin IX indicated less hemoglobin breakdown. Interestingly, increases in taurallocholic acid and 5bcyprinolsulfate, two bile acids involved in fat processing, were also detected. However, no studies have reported their functions in autoimmune or inflammatory diseases.

\section{Conclusion}

QJF could inhibit the activity of the complement system and resume the normal levels of metabolites in MG patients. The findings of the present and previous studies suggest that QJF is an effective drug for treatment of MG.

\section{Abbreviations \\ QJF: Qiangji Jianli Fang; MG: Myasthenia gravis; AChRAb: Anti-acetylcholine receptor antibody; MuSKAb: Anti-muscle-specific receptor tyrosine kinase antibody; CM: Chinese medicine; 2-DE: Two-dimensional gel electrophoresis; MALDI-TOF MS: Matrix-assisted laser desorption/ionization time-of-flight mass spectrometry; LC-FTMS: Liquid chromatography Fourier transform mass spectrometry; CHAPS: 3-[(3-cholamidopropyl)-dimethylammonio]-1- propanesulfonate; Vhs: Voltage hours; ACN: Acetonitrile; GABA: $\gamma^{-}$ aminobutyric acid.}

\section{Competing interests}

The authors declare that they have no competing interests.

\section{Authors' contributions}

$C W, Y L, Z C$ and $S N$ designed the study. $C W$ and $Y L$ conducted the experiments and contributed equally to the study. CW, YL, YK and SN wrote the manuscript. $\mathrm{ZC}, \mathrm{XL}, \mathrm{HQ}, \mathrm{HZ}$ and $\mathrm{JC}$ recruited patients, performed the treatment and collected the samples. All authors read and approved the final version of the manuscript.

\section{Acknowledgments}

We thank Dr. Liang Willmann for English proofreading. This work was supported by a major project of the Chinese National Program for Fundamental Research and Development (973 Program) (2005CB523502) and Hong Kong University Grants Committee Area of Excellence (UGC AoE) Plant and Agricultural Biotechnology Project AoE-B-07/09.

\footnotetext{
Author details

${ }^{1}$ School of Life Sciences, The Chinese University of Hong Kong, Shatin, N.T, Hong Kong SAR, China. ${ }^{2}$ Department of Nuclear Medicine, Guangzhou University of Chinese Medicine, Guangzhou, China. ${ }^{3}$ School of Basic Medicine, Guangzhou University of Chinese Medicine, Guangzhou, China. ${ }^{4}$ School of Biomedical Sciences, The Chinese University of Hong Kong, Hong Kong SAR, China.
}

Received: 10 February 2012 Accepted: 18 June 2012 Published: 28 July 2012

\section{References}

1. McGrogan A, Sneddon S, de Vries CS: The incidence of myasthenia gravis: a systematic literature review. Neuroepidemiology 2010, 34:171-183.

2. Gomez AM, Van Den Broeck J, Vrolix K, Janssen SP, Lemmens MA, Van Der Esch E, Duimel H, Frederik P, Molenaar PC, Martínez-Martínez P, De Baets MH, Losen M: Antibody effector mechanisms in myasthenia gravis-pathogenesis at the neuromuscular junction. Autoimmunity 2010, 43:353-370.

3. Giraud M, Vandiedonck C, Garchon HJ: Genetic factors in autoimmune myasthenia gravis. Ann N Y Acad Sci 2008, 1132:180-192.

4. Cavalcante P, Barberis M, Cannone M, Baggi F, Antozzi C, Maggi L, Cornelio F, Barbi M, Dido P, Berrih-Aknin S, Mantegazza R, Bernasconi P: Detection of poliovirus-infected macrophages in thymus of patients with myasthenia gravis. Neurology 2010, 74:1118-1126.

5. Stefansson K, Dieperink ME, Richman DP, Marton LS: Sharing of epitopes by bacteria and the nicotinic acetylcholine receptor: a possible role in the pathogenesis of myasthenia gravis. Ann N Y Acad Sci 1987, 505:451-460.

6. Mantegazza R, Bonanno S, Camera G, Antozzi C: Current and emerging therapies for the treatment of myasthenia gravis. Neuropsychiatric Disease and Treatment 2011, 7:151-160.

7. Tüzün E, Huda R, Christadoss P: Complement and cytokine based therapeutic strategies in myasthenia gravis. J Autoimmun 2011, 37:136-143.

8. Chien PJ, Yeh JH, Chiu HC, Hsueh YM, Chen CT, Chen MC, Shih CM: Inhibition of peripheral blood natural killer cell cytotoxicity in patients with myasthenia gravis treated with plasmapheresis. Eur J Neurol 2011, 18:1350-1357

9. García-Carrasco M, Escarcega RO, Fuentes-Alexandro S, Riebeling C, Cervera R: Therapeutic options in autoimmune myasthenia gravis. Autoimmun Rev 2007, 6:373-378.

10. Lin H, Liu J, Zhang Y: Developments in cancer prevention and treatment using traditional Chinese medicine. Frontiers of Medicine 2011, 5:127-133.

11. Liu ZL, Liu JP, Zhang AL, Wu Q, Ruan Y, Lewith G, Visconte D: Chinese herbal medicines for hypercholesterolemia. Cochrane Database Syst Rev 2011, 7:CD008305.

12. He DY, Dai SM: Anti-inflammatory and immunomodulatory effects of paeonia lactiflora pall., a traditional chinese herbal medicine. Frontiers in Pharmacology 2011, 2:10.

13. Sun $Y$, Zang Z, Xu X, Zhang Z, Zhong L, Zan W, Zhao Y, Sun L: Experimental investigation of the immunoregulatory and antiinflammatory effects of the traditional Chinese medicine "Li-Yan Zhi-Ke Granule" for relieving chronic pharyngitis in rats. Mol Biol Rep 2011, 38:199-203.

14. Pan W, Kwak S, Liu Y, Sun Y, Fang Z, Qin B, Yamamoto Y: Traditional chinese medicine improves activities of daily living in Parkinson's disease. Parkinson's Disease 2011, 2011:789506.

15. Ho LJ, Lai JH: Chinese herbs as immunomodulators and potential disease-modifying antirheumatic drugs in autoimmune disorders Curr Drug Metab 2004, 5:181-192.

16. Lai JH: Immunomodulatory effects and mechanisms of plant alkaloid tetrandrine in autoimmune diseases. Acta Pharmacol Sin 2002, 23:1093-1101.

17. Chen ZJ, Li YS, Li YK: Review of study on mechanism of traditional Chinese medicine in treating autoimmunity disease. Journal of Chinese Medicinal Materials 2003, 26:218-221.

18. Huang CF, Lin SS, Liao PH, Young SC, Yang CC: The immunopharmaceutical effects and mechanisms of herb medicine. Cell Mol Immunol 2008, 5:23-31.

19. Chen XK, Wang LF, Zhao H, Wu YH, Chen ZX: Effect of Qiangji Jianli Fang on the serum levels of cytokines (IL-2, TNF, IL-6) in rat models of spleen-kidney deficiency syndrome. Journal of Radioimmunology 2010, 23:282-284.

20. Liu XB, Deng GZ: Clinical investigation of Qiangji JianLi Fang on myasthenia gravis patients with spleen-kidney deficiency syndrome. Traditional Chinese Drug Research \& Clinical Pharmacology 2004, 15:361.

21. Deng TT, Li RX, Li SHM, Zhang SHP, Liu XB, Yang WH, Deng GZ: Curative effect of Qiang J Jian $L$ capsule in a randomized, double-blind, self-cross-controlled test for myasthenia gravis. Journal of Guangzhou University of Traditional Chinese Medicine 1992, 9:7-10. 
22. Ali Z, Khan SI, Khan IA: New cycloartane-type triterpene arabinosides from the roots of Actaea podocarpa and their biological study. Planta Med 2007, 73:699-703.

23. Yamada H, Kiyohara H, Cyong JC, Otsuka Y: Studies on polysaccharides from Angelica acutiloba--IV. Characterization of an anti-complementary arabinogalactan from the roots of Angelica acutiloba Kitagawa. Mol Immunol 1985, 22:295-304

24. Jiang JB, Qiu JD, Yang LH, He JP, Smith GW, Li HQ: Therapeutic effects of astragalus polysaccharides on inflammation and synovial apoptosis in rats with adjuvant-induced arthritis. Int J Rheum Dis 2010, 13:396-405.

25. Liu J, Hu X, Yang Q, Yu Z, Zhao Z, Yi T, Chen H: Comparison of the immunoregulatory function of different constituents in radix astragali and radix hedysari. J Biomed Biotechnol 2010, 2010:479426.

26. Zhao P, Su G, Xiao X, Hao E, Zhu X, Ren J: Chinese medicinal herb Radix Astragali suppresses cardiac contractile dysfunction and inflammation in a rat model of autoimmune myocarditis. Toxicol Lett 2008, 182:29-35.

27. Sun YX: Immunological adjuvant effect of a water-soluble polysaccharide, CPP, from the roots of Codonopsis pilosula on the immune responses to ovalbumin in mice. Chem Biodivers 2009, 6:890-896.

28. Wang ZT, Ng TB, Yeung HW, Xu GJ: Immunomodulatory effect of a polysaccharide-enriched preparation of Codonopsis pilosula roots. Gen Pharmacol 1996, 27:1347-1350.

29. Kim SH, Jung HN, Lee KY, Kim J, Lee JC, Jang YS: Suppression of Th2-type immune response-mediated allergic diarrhea following oral administration of traditional Korean medicine: Atractylodes macrocephala Koidz. Immunopharmacol Immunotoxicol 2005, 27:331-343.

30. Lee JC, Lee KY, Son YO, Choi KC, Kim J, Kim SH, Chung GH, Jang YS: Stimulating effects on mouse splenocytes of glycoproteins from the herbal medicine Atractylodes macrocephala Koidz. Phytomedicine 2007, 14:390-395.

31. Yang T, Jia M, Zhou S, Pan F, Mei Q: Antivirus and immune enhancement activities of sulfated polysaccharide from Angelica sinensis. Int J Biol Macromol 2012, 50:768-772.

32. Nishida M, Yoshimitsu H, Nohara T: Three cycloartane glycosides from Cimicifuga rhizome and their immunosuppressive activities in mouse allogeneic mixed lymphocyte reaction. Chem Pharm Bull(Tokyo) 2003, 51:354-356.

33. Pan RL, Chen DH, Si JY, Zhao XH, Li Z, Cao L: Immunosuppressive effects of new cyclolanostane triterpene diglycosides from the aerial part of Cimicifuga foetida. Arch Pharm Res 2009, 32:185-190.

34. Wang Z, Li H, Xu H, Yue XL, Cheng XQ, Hou WJ, Zhang YY, Chen DF: Beneficial effect of Bupleurum polysaccharides on autoimmune disease induced by Campylobacter jejuni in BALB/c mice. J Ethnopharmacol 2009, 124:481-487.

35. Ushio $Y$, Oda $Y$, Abe $\mathrm{H}$ : Effect of saikosaponin on the immune responses in mice. Int J Immunopharmacol 1991, 13:501-508.

36. Shi Q, Liu Z, Yang Y, Geng P, Zhu YY, Zhang Q, Bai F, Bai G: Identification of anti-asthmatic compounds in Pericarpium citri reticulatae and evaluation of their synergistic effects. Acta Pharmacol Sin 2009, 30:567-575.

37. Yang G, Yu Y: Immunopotentiating effect of traditional Chinese drugsginsenoside and glycyrrhiza polysaccharide. Proc Chin Acad Med Sci Peking Union Med Coll 1990, 5:188-193.

38. Lee JY, Lee JH, Park JH, Kim SY, Choi JY, Lee SH, Kim YS, Kang SS, Jang EC, Han $Y$ : Liquiritigenin, a licorice flavonoid, helps mice resist disseminated candidiasis due to Candida albicans by Th1 immune response, whereas liquiritin, its glycoside form, does not. Int Immunopharmacol 2009, 9:632-638.

39. Keesey J, Aarli J: Something in the Blood? A history of the autoimmune hypothesis regarding myasthenia gravis. J Hist Neurosci 2007, 16:395-412.

40. Yeh JH, Wang SH, Chien PJ, Shih CM, Chiu HC: Changes in serum cytokine levels during plasmapheresis in patients with myasthenia gravis. Eur $J$ Neurol 2009, 16:1318-1322.

41. Na SJ, So SH, Lee KO, Choi YC: Elevated serum level of interleukin-32a in the patients with myasthenia gravis. J Neurol 2011, 258:1865-1870.

42. Kim JY, Yang Y, Moon JS, Lee EY, So SH, Lee HS, Park KD, Choi YC: Serum BAFF expression in patients with myasthenia gravis. J Neuroimmunol 2008, 199:151-154.

43. Al-Mubarak R, Vander Heiden J, Broeckling CD, Balagon M, Brennan PJ, Vissa VD: Serum metabolomics reveals higher levels of polyunsaturated Fatty acids in lepromatous leprosy: potential markers for susceptibility and pathogenesis. PLoS Negl Trop Dis 2011, 5:e1303.
44. Hortin GL: The MALDI-TOF mass spectrometric view of the plasma proteome and peptidome. Clin Chem 2006, 52:1223-1237.

45. Liu P, Zhang YY, Qiao J: Establishment and analysis of serum two-dimensional gel electrophoresis profiles of myasthenia gravis patients with spleen and kidney deficiency syndrome. Zhong $X_{i} Y_{i}$ Jie He Xue Bao 2007, 5:150-154.

46. Cheng C, Wu G, Yeung SC, Li R, Bella AE, Pang J, Zhong FT, Luo H, Jin Y, Pan J: Serum protein profiles in myasthenia gravis. Ann Thorac Surg 2009, 88:1118-1123

47. Lu YH, Wang CM, Chen ZX, Zhao H, Chen JY, Liu XB, Zhao H, Kwan YW, Lin $H Q$, Ngai SM: Serum metabolomics for the diagnosis and classification of myasthenia gravis. Metabolomics. in press.

48. Osserman KE, Genkins G: Studies in myasthenia gravis: review of a twenty-year experience in over 1200 patients. The Mount Sinai Journal of Medicine, New York 1971, 38:497-537.

49. Liu J, Zhu P, Peng J, Li K, Du J, Gu J, Ou Y: Identification of disease-associated proteins by proteomic approach in ankylosing spondylitis. Biochem Biophys Res Commun 2007, 357:531-536.

50. Mackiewicz A, Khan MA, Reynolds TL, van der Linden S, Kushner I: Serum $\lg A$, acute phase proteins, and glycosylation of alpha 1-acid glycoprotein in ankylosing spondylitis. Ann Rheum Dis 1989, 48:99-103.

51. Sottrup-Jensen L: Alpha-macroglobulins: structure, shape, and mechanism of proteinase complex formation. J Biol Chem 1989, 264:11539-11542.

52. Howard FM Jr, Silverstein MN, Mulder DW: The coexistence of myasthenia gravis and pernicious anemia. Am J Med Sci 1965, 250:518-526.

53. Harrison RA, Farries TC, Northrop FD, Lachmann PJ, Davis AE: Structure of C3f, a small peptide specifically released during inactivation of the third component of complement. Complement 1988, 5:27-32.

54. Liu A, Lin H, Liu Y, Cao X, Wang X, Li Z: Correlation of C3 level with severity of generalized myasthenia gravis. Muscle Nerve 2009, 40:801-808.

55. Tüzün E, Scott BG, Goluszko E, Higgs S, Christadoss P: Genetic evidence for involvement of classical complement pathway in induction of experimental autoimmune myasthenia gravis. J Immunol 2003, 171:3847-3854.

56. Thielens NM, Colomb MG: A model system for the study of the assembly and regulation of human complement C3 convertase (classical pathway). Eur J Immunol 1986, 16:617-622.

57. Soltys J, Kusner LL, Young A, Richmonds C, Hatala D, Gong B, Shanmugavel $\checkmark$, Kaminski HJ: Novel complement inhibitor limits severity of experimentally myasthenia gravis. Ann Neurol 2009, 65:67-75.

58. Hilgenfeldt U, Linke R, Riester U, König W, Breipohl G: Strategy of measuring bradykinin and kallidin and their concentration in plasma and urine. Anal Biochem 1995, 228:35-41.

59. Bhat R, Axtell R, Mitra A, Miranda M, Lock C, Tsien RW, Steinman L: Inhibitory role for GABA in autoimmune inflammation. Proc Natl Acad Sci USA 2010, 107:2580-2585.

60. Kelley JM, Hughes LB, Bridges SL Jr: Does gamma-aminobutyric acid (GABA) influence the development of chronic inflammation in rheumatoid arthritis? J Neuroinflammation 2008, 5:1.

61. Ernster L, Dallner $G$ : Biochemical, physiological and medical aspects of ubiquinone function. Biochim Biophys Acta 1995, 1271:195-204.

62. Schmelzer $C$, Lindner I, Rimbach $G$, Niklowitz $P$, Menke T, Döring F: Functions of coenzyme Q10 in inflammation and gene expression. Biofactors 2008, 32:179-183.

63. Kim S, Hong I, Hwang JS, Choi JK, Rho HS, Kim DH, Chang I, Lee SH, Lee $\mathrm{MO}$, Hwang JS: Phytosphingosine stimulates the differentiation of human keratinocytes and inhibits TPA-induced inflammatory epidermal hyperplasia in hairless mouse skin. Mol Med 2006, 12:17-24.

64. Shimada H, Rajagopalan LE: Rho-kinase mediates lysophosphatidic acid-induced IL-8 and MCP-1 production via p38 and JNK pathways in human endothelial cells. FEBS Lett 2010, 584:2827-2832.

doi:10.1186/1749-8546-7-16

Cite this article as: Wang et al: Serum proteomic, peptidomic and metabolomic profiles in myasthenia gravis patients during treatment with Qiangji Jianli Fang. Chinese Medicine 2012 7:16. 